\title{
Synthesis of Magnetite/ Hematite/ Iron Nanocomposites by the Low Voltage Arc Discharge in Water in the Presence of External Magnetic Field
}

\author{
Hassan Karami ${ }^{1,2, *}$, Fariba Goli ${ }^{1}$, Juliet Ordoukhanian ${ }^{1}$ \\ ${ }^{1}$ Department of Chemistry, Payame Noor University, 19395-4697, Tehran, I.R. of Iran \\ ${ }^{2}$ Nano Research Laboratory, Department of Chemistry, Payame Noor University, Abhar, I.R. of Iran \\ *E-mail: karami_h@yahoo.com
}

doi: $10.20964 / 110403074$

Received: 10 September 2015 / Accepted: 12 October 2015 / Published: 1 March 2016

\begin{abstract}
A new method for the synthesis of magnetite/ hematite/ iron nanocomposites (MHINC) is introduced. In this method, a low-voltage arc is discharged between two iron electrodes in distilled water while an external magnetic field with the nominal power of 0.4-1.6 $\mathrm{T}$ is applied during synthesis. The measured magnetic field exactly on the anode tip is 80 to $210 \mathrm{mT}$. By arc discharge, iron is oxidized to iron oxides. The synthesized samples are characterized by SEM, TEM, XRD and VSM techniques. The sizes distributions of some samples are identified by dynamic light scattering (DLS) test. The obtained results show the presence of the external magnetic field can decrease the particle sizes and also increases the saturation of magnetization and the transformation rate of iron into iron oxide in nanocomposite.
\end{abstract}

Keywords: External magnetic field; Arc discharge; Nanocomposite; Iron; Magnetite; Hematite

\section{$\underline{\text { FULL TEXT }}$}

(C) 2016 The Authors. Published by ESG (www.electrochemsci.org ). This article is an open access article distributed under the terms and conditions of the Creative Commons Attribution license (http://creativecommons.org/licenses/by/4.0/). 